Fothergill, P. G. \& R. Ashcroft (1955). J. gen. Microbiol. 12, 387-395

\title{
The Nutritional Requirements of Venturia inaequalis
}

\author{
By P. G. FOTHERGILL \\ Botany Department, King's College, Nerwcastle upon Tyne 1 \\ AND ROSALIND ASHCROFT \\ Pathology Department, Royal Victoria Infirmary, Newcastle upon Tyne 1
}

SUMMARY: A study of the nutritional requirements of Venturia inaequalis showed that this parasitic fungus grew well in a medium containing: $\mathrm{K}_{2} \mathrm{HPO}_{4}, 0.004 \mathrm{M}$; $\mathrm{MgSO}_{4} .7 \mathrm{H}_{2} \mathrm{O}, 0.002 \mathrm{M} ; \mathrm{NH}_{4} \mathrm{NO}_{3}, 0.0375 \mathrm{M}$; glucose $4 \%(\mathrm{w} / \mathrm{v}) ; \mathrm{Zn}$ and $\mathrm{Mn} 2$ p.p.m.; thiamine, pyridoxine, nicotinic acid, folic acid, ascorbic acid. Without thiamine practically no growth of the fungus took place; omission of pyridoxine had nearly as adverse an effect. Raffinose and cellobiose were the best carbon sources; glucose also gave a good yield of mycelium. Statistical analysis of factorial experiments indicated that a correct balance between the mineral constituents of the medium and between the carbon and nitrogen sources is essential in order to obtain a high yield of mycelium.

Apple scab is one of the commonest orchard diseases in temperate regions. The disease attacks all parts of the tree and when infection of the fruit is severe the yield of marketable apples may be decreased by as much as $50 \%$. This disease is caused by the fungus Venturia inaequalis (Cooke) Winter, an ascomycete. The conidial phase, which is the more important stage from a pathological standpoint, was at one time called Fusicladium dendriticum (Wallr.) Fol.; this stage is found on all living parts of the host. The perithecial stage is less noticeable and occurs only on over-wintered fallen leaves.

Most of the work done on Venturia inaequalis in the past has concentrated on the genetics of disease resistance and susceptibility. Johnstone (1931) suggested that resistance to the fungus was not due to any single factor and appeared to depend on the physiological relationship between host and parasite, while the work of Keitt \& Langford (1941) indicated that it might be connected with the nutrition of the fungus. The nutritional requirements of $V$. inaequalis have not previously been comprehensively investigated; the present paper describes results of work along these lines.

\section{METHODS}

Stock cultures of Venturia inaequalis were grown on malt-extract agar slopes containing apple leaf decoction; this MEAL medium was prepared as follows. Air-dried 'Bramley's Seedling' apple leaves (25 g.) were boiled in $500 \mathrm{ml}$. distilled water for $30 \mathrm{~min}$. Malt extract ( $5 \mathrm{~g}$.) and agar (25 g,) were dissolved in distilled water and the filtered leaf decoction added to this mixture, which was then made up to a final volume of $1 \mathrm{l}$. The inoculum for all experiments was prepared by adding $15 \mathrm{ml}$. sterile distilled water to a $6 \times \frac{3}{4}$ in. tube

G. Microb. XII 
containing a well-grown culture on agar (30 days old). The surface of the agar was scratched with a sterile needle, and $1 \mathrm{ml}$. of the resultant mycelial suspension was then used as inoculum for each experimental flask of liquid medium. It was found by experience that the exact amount of the inoculum did not appreciably affect growth.

In the nutritional experiments $30 \mathrm{ml}$. volumes of medium were used in $150 \mathrm{ml}$. Erlenmeyer flasks, with five replicates for each variation of medium. Sterile phosphate solutions were added to the flasks after autoclaving. After incubation the mycelial felts were harvested, dried at $95^{\circ}$ and weighed, amounts of growth being expressed as mg. dry wt./flask.

\section{RESULTS}

Preliminary experiments on MEAL agar showed that $20^{\circ}$ was the optimum temperature for mycelial growth which attained a maximum in 30 days. Various simple defined media containing glucose and mineral salts, such as Czapek-Dox or one devised by Ezekiel, Taubenhaus \& Fudge (1934) were tried but growth was extremely poor. The best simple defined medium (SD) found contained: $\mathrm{K}_{2} \mathrm{HPO}_{4}, 0.008 \mathrm{M} ; \mathrm{MgSO}_{4} .7 \mathrm{H}_{2} \mathrm{O}, 0.003 \mathrm{M} ; \mathrm{KCl}, 0.002 \mathrm{M} ; \mathrm{NH}_{4} \mathrm{NO}_{3}$, $0.0125 \mathrm{M}$; glucose, $4 \%(\mathrm{w} / \mathrm{v}) ; \mathrm{MnSO}_{4} .4 \mathrm{H}_{2} \mathrm{O}$ and $\mathrm{ZnSO}_{4} .7 \mathrm{H}_{2} \mathrm{O}$ at 2 p.p.m. [Here and throughout the $\mathrm{m}$ concentrations refer to the strengths of solutions calculated from the amounts of salts added; they do not refer to undissociated molecules in solution.] Iron was not added to this medium because it was invariably present in the 'Analar' reagents used. Sterile phosphate solution was added aseptically after the rest of the medium had been autoclaved. In this SD medium the weight of mycelium obtained under the standard conditions of incubation was $8.2 \mathrm{mg} . / \mathrm{flask}$.

\section{The effect of various vitamins on growth}

To improve the growth on SD medium the effect of adding various vitamin supplements was examined. The following substances were tested in the amounts shown $(\mu \mathrm{g} . / \mathrm{ml}$. final concentration): biotin $(0.4)$, folic acid (2), thiamine (200), pyridoxine (1200), nicotinic acid (600), riboflavin (200), ascorbic acid (16).

Replicate flasks (5) were prepared which contained SD medium + the seven vitamins, or lacking one vitamin omitted in turn from the medium. The effect of adding asparagine was also tested. The results are shown in Table 1. It is seen that the addition of the 7 vitamins to the best mineral medium (SD) increased amount of growth nearly 18 times. The effect of the different vitamins varied considerably. Omission of biotin or riboflavin had least effect and the omission of pyridoxine, folic acid, nicotinic acid, ascorbic acid or thiamine had increasingly greater effects, in that order, in depressing growth. The effect of ascorbic acid is interesting; when it was omitted from the full SDV medium ( $=\mathrm{SD}$ medium +7 vitamins) growth was decreased by $75 \%$. This seems to be an unrecorded effect of ascorbic acid on mycelial fungi. Thiamine, ascorbic 
acid, nicotinic acid, folic acid and pyridoxine, which had the most marked effect on growth, were added to all subsequent cultures unless otherwise stated. Ammonium nitrate as nitrogen source gave much better growth than asparagine.

Table 1. The effects of certain vitamins and other constituents of the medium on the growth of Venturia inaequalis

Mean dry weight mycelium/flask expressed as percentage of the value for growth on complete SDV medium

\begin{tabular}{|c|c|c|c|}
\hline Medium & $\begin{array}{c}\text { Mean } \\
\text { dry-wt. } \\
(\%)\end{array}$ & Medium & $\begin{array}{c}\text { Mean } \\
\text { dry-wt } \\
(\%)\end{array}$ \\
\hline Glucose mineral salts (SD) & 6 & SDV minus biotin & 91 \\
\hline SD medium +7 vitamins (SDV) & 100 & SDV minus folic acid & 58 \\
\hline SDV but $0.0125 \mathrm{M}$-asparagine* & 9 & SDV minus thiamine & 16 \\
\hline SD but 0.0125 M-asparagine* & 25 & SDV minus pyridoxine & 63 \\
\hline $\mathrm{SDV}$ minus $\mathrm{NH}_{4} \mathrm{NO}_{3}$ & 2 & SDV minus riboflavin & 89 \\
\hline SDV minus $\mathrm{K}_{2} \mathrm{HPO}_{4}$ & $\mathbf{3}$ & SDV minus nicotinic acid & 42 \\
\hline $\mathrm{SDV}$ minus $\mathrm{MgSO}_{4}$ & 29 & SDV minus ascorbic acid & 26 \\
\hline SDV minus $\mathrm{KCl}$ & 86 & & \\
\hline SDV minus Fe & 100 & & \\
\hline SDV minus Mn & 92 & & \\
\hline SDV minus $\mathrm{Zn}$ & 64 & & \\
\hline
\end{tabular}

* Asparagine replacing $\mathrm{NH}_{4} \mathrm{NO}_{3}$.

The effect of the separate medium constituents and the determination of the optimum $\mathrm{pH}$ value for growth

Glucose and various mineral constituents were omitted in turn from the SDV medium in another experiment. Omission of ammonium nitrate and potassium hydrogen phosphate resulted in practically no growth, while omission of other minerals, with the exception of iron, appreciably diminished growth (Table 1).

For the determination of the optimum $\mathrm{pH}$ value for the growth of Venturia inaequalis the basal medium containing $\mathrm{NH}_{4} \mathrm{NO}_{3}, \mathrm{~K}_{2} \mathrm{HPO}_{4}, \mathrm{MgSO}_{4}, \mathrm{KCl}, \mathrm{Mn}$, $\mathrm{Zn}$, glucose and the five vitamins thiamine, ascorbic acid, nicotinic acid, folic acid, pyridoxine was used. Cultures were grown in this medium adjusted with $\mathrm{HCl}$ or $\mathrm{Na}_{2} \mathrm{CO}_{3}$ to a range of $\mathrm{pH}$ values between 2.5 and 7.0 at 0.3 unit intervals. The phosphate solution was also adjusted and added separately to the medium after sterilization. The optimum $\mathrm{pH}$ value was found to be $\mathbf{5 \cdot 8}$. There was a rapid decrease of growth as the $\mathrm{pH}$ value of the medium decreased to $3 \cdot 4$, at which value there was no growth. There was a much slower decrease in growth as the $\mathrm{pH}$ value was increased above $5 \cdot 8$; growth was still reasonably

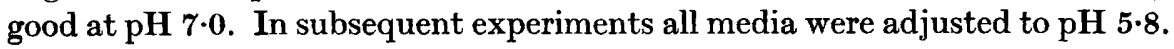

\section{The utilization of carbon compounds}

The utilization of different carbon compounds by Venturia inaequalis was determined. The basal SD medium + the five vitamins was used but glucose was replaced by other carbon compounds at $4 \%(w / v)$. 
When acids were added the $\mathrm{pH}$ was adjusted to $5 \cdot 8$ with sodium carbonate. The yields of organism (dry weight) expressed as percentage of the yield on glucose were as follows: 130-100\%, cellobiose, raffinose; 100-75\%, dextrin, inulin; 75-50\%, fructose, maltose, rhamnose; 50-25 \%, sucrose; 25-10\%, sorbitol, salicin; 10-1\%, galactose, mannitol, dulcitol, malate, succinate, fumarate, glycogen, starch; no growth on inositol, tartrate, oxalate, salicylate, citrate or trehalose.

Thus cellobiose, a glucoside, and raffinose, a trisaccharide, gave better yields than glucose. Dextrin, a glucose polysaccharide, and inulin, a fructose polysaccharide, gave quite good yields. The yield with sucrose was unexpectedly low. The pentoses, some of the hexoses and disaccharides and the organic acids were hardly utilized, if at all. It is evident that certain carbohydrates are readily utilizable by Venturia inaequalis. With several lines of this fungus Leben \& Keitt (1948) found that cellobiose, dextrin, fructose, glucose, maltose, mannitol, mannose, mellibiose, raffinose or sucrose were good sources for all the strains tested, while organic acids were inhibitory or poorly used. The results given here in the main confirm those of Leben \& Keitt, although there are important differences. The present experiments, however, are not strictly comparable with those of Leben \& Keitt who used a malt-agar basal medium and recorded their results arbitrarily by visual comparison of growth between the tests and controls. In our experiments glucose was the best commonly available carbon compound.

\section{First factorial experiment; variation of amounts of $\mathrm{K}_{2} \mathrm{HPO}_{4}, \mathrm{MgSO}_{4}$ and $\mathrm{KCl}$ added}

The basal physical and chemical requirements of a culture medium for Venturia inaequalis having been determined, the effect of the balance of the chemicals used in the medium was investigated. The experiments were designed to show statistically whether or not a balance between the salts is necessary for best growth under given conditions. The factorial design of the experiments also determines the direct effect of the individual salts in the medium and the interaction between them simultaneously.

In this experiment $\mathrm{K}_{2} \mathrm{HPO}_{4}$ and $\mathrm{MgSO}_{4}$ were studied at three concentrations, while $\mathrm{KCl}$ was either present or absent; the experiment was planned to allow an analysis of variance to be drawn up. Eighteen possible solutions were set up each in five replicates, giving a total of 90 cultures in any one experiment. Growth was recorded as dry weight of mycelium. All the mixtures had an initial $\mathrm{pH}$ value suitable for good growth of this fungus; the acidity uniformly decreased as growth proceeded. The results are shown in Table 2 which also shows the analysis of variance.

There was a significant difference between the highest and lowest concentrations of $\mathrm{K}_{2} \mathrm{HPO}_{4}$. There was no significant difference between the three concentrations of $\mathrm{MgSO}_{4}$ but the highest concentration gave the highest mean weight of mycelium. The presence or absence of $\mathrm{KCl}$ made practically no difference to the mycelial weight. This does not mean that chloride is not 
essential, small amounts were probably present as impurity, but it does indicate that the organism requires little, if any, chlorine. No addition of chloride was necessary under our conditions. Potassium was present in other components of the medium and its addition as $\mathrm{KCl}$ had no appreciable effect on growth.

Table 2. Dry weight of mycelium of Venturia inaequalis after 30 days growth at $20^{\circ}$ on media with different concentrations of certain components

Concentrations of $\mathrm{K}_{2} \mathrm{HPO}_{4}: \mathrm{P}_{1}, \mathrm{P}_{2}, \mathrm{P}_{3}=0.004 \mathrm{M}, 0.008 \mathrm{M}, 0.012 \mathrm{M}$; of $\mathrm{MgSO}_{4}: \mathrm{Mg}_{1}, \mathrm{Mg}_{2}$, $\mathrm{Mg}_{3}=0.0015 \mathrm{M}, 0.003 \mathrm{M}, 0.006 \mathrm{M}$; of $\mathrm{KCl}: 0.002 \mathrm{M}$ or none. Difference required between weights for odds of 99:1=6.2 mg. for $\mathrm{K}_{2} \mathrm{HPO}_{4}$ and $\mathrm{MgSO}_{4}$ and $5 \cdot 1 \mathrm{mg}$. for $\mathrm{KCl}$.

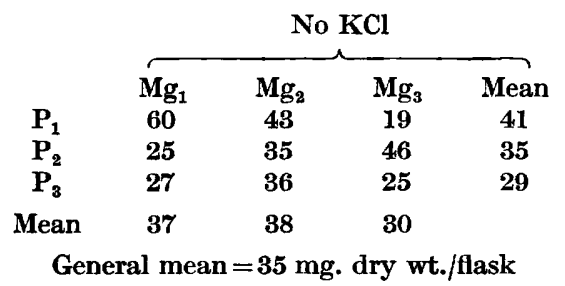

\begin{tabular}{ccccc} 
& \multicolumn{4}{c}{} \\
$\mathrm{Mg}_{1}$ & $\mathbf{5 4}$ & $\mathrm{Mg}_{2}$ & $\mathrm{Mg}_{3}$ & Mean \\
$\mathbf{P}_{2}$ & $\mathbf{2 0}$ & 41 & $\mathbf{3 3}$ & 39 \\
$\mathbf{P}_{3}$ & 36 & 26 & 42 & 35 \\
Mean & 37 & 35 & 34 & \\
\multicolumn{3}{l}{ General mean $=$} & $\mathbf{3 5}$ mg. dry wt./flask
\end{tabular}

Analysis of variance

(Required ' $F$ ' and ' $t$ ' values taken from Snedecor's tables (1934).)

\begin{tabular}{|c|c|c|c|c|c|c|}
\hline \multirow[b]{2}{*}{ Variance } & \multirow[b]{2}{*}{ D.F. } & \multirow[b]{2}{*}{$\begin{array}{l}\text { Sum of } \\
\text { Squares }\end{array}$} & \multirow[b]{2}{*}{$\begin{array}{c}\text { Mean } \\
\text { Square }\end{array}$} & \multicolumn{3}{|c|}{$\stackrel{F}{\text { Required odds }}$} \\
\hline & & & & Found & $99: 1$ & $19: 1$ \\
\hline Total & 89 & 16,120 & $181 \cdot 13$ & $\longrightarrow$ & 一 & - \\
\hline $\mathrm{K}_{2} \mathrm{HPO}_{4}$ & $\mathbf{2}$ & $899 \cdot 99$ & $449 \cdot 99$ & $5 \cdot 397$ & $4 \cdot 88$ & $3 \cdot 11$ \\
\hline $\mathrm{MgSO}_{4}$ & $\overline{2}$ & $505 \cdot 67$ & $252 \cdot 84$ & $3 \cdot 033$ & $4 \cdot 88$ & $3 \cdot 11$ \\
\hline $\mathrm{KCl}$ & 1 & 0.0587 & 0.059 & 一 & - & - \\
\hline $\mathrm{K}_{2} \mathrm{HPO}_{4} \times \mathrm{MgSO}_{4}$ & 4 & $7,899 \cdot 78$ & $1,974-94$ & $\mathbf{2 3 \cdot 6 8 9}$ & $\mathbf{3 \cdot 5 6}$ & $\mathbf{2} \cdot 49$ \\
\hline $\mathrm{K}_{2} \mathrm{HPO}_{4} \times \mathrm{KCl}$ & 2 & $297 \cdot 67$ & $148 \cdot 84$ & 1.785 & $4 \cdot 88$ & $3 \cdot 11$ \\
\hline $\mathrm{MgSO}_{4} \times \mathrm{KCl}$ & 2 & $181 \cdot 40$ & $90 \cdot 7$ & $1 \cdot 088$ & $4 \cdot 88$ & $3 \cdot 11$ \\
\hline 2nd order interaction error & 76 & $6, \mathbf{3 3 5} \cdot 85$ & $83 \cdot 7$ & - & - & 一 \\
\hline
\end{tabular}

The analysis of variance shows the interaction of $\mathrm{K}_{2} \mathrm{HPO}_{4}$ and $\mathrm{MgSO}_{4}$ to be highly significant. The opposite effect was obtained when the concentration of $\mathrm{MgSO}_{4}$ was increased with the low concentration of $\mathrm{K}_{2} \mathrm{HPO}_{4}$ to that obtained with $0.008 \mathrm{M}-\mathrm{K}_{2} \mathrm{HPO}_{4}$. Thus the mean weight of mycelium decreased as the concentration of $\mathrm{MgSO}_{4}$ increased with $0.004 \mathrm{M}-\mathrm{K}_{2} \mathrm{HPO}_{4}$. With $0.008 \mathrm{M}$ $\mathrm{K}_{2} \mathrm{HPO}_{4}$ the mean weight increased as the concentration of $\mathrm{MgSO}_{4}$ increased. Thus a proper physiological balance between these two salts is important. There was only a slight difference in the mean weights of mycelium for $0.004 \mathrm{M}-\mathrm{K}_{2} \mathrm{HPO}_{4}$ with $0.003 \mathrm{M}-\mathrm{MgSO}_{4}$, and for $0.008 \mathrm{M}-\mathrm{K}_{2} \mathrm{HPO}_{4}$ with $0.006 \mathrm{M}-$ $\mathrm{MgSO}_{4}$ and the concentrations of these two salts in the latter solution were exactly double those of the former, showing that it is not only the concentration of the salts but the balance between them which is important in the nutrition of this fungus. At the highest concentration of $\mathrm{K}_{2} \mathrm{HPO}_{4}$, variation in that of $\mathrm{MgSO}_{4}$ had no significant effect, suggesting that the concentration 
of the $\mathrm{K}_{2} \mathrm{HPO}_{4}$ was too high for good growth. The best growth was obtained with the lowest concentration of both salts.

The other interactions, $\mathrm{K}_{2} \mathrm{HPO}_{4}$ with $\mathrm{MgSO}_{4}$ and $\mathrm{KCl}$, were not significant and hence the results of the second-order interaction were grouped with the error in the analysis of variance. Best growth was obtained with the lower concentrations of $\mathrm{K}_{2} \mathrm{HPO}_{4}$ and $\mathrm{MgSO}_{4}$, while the addition or omission of $\mathrm{KCl}$ was of no consequence. It is evident that the main effect of the individual salts cannot be extended indefinitely because a correct relationship between the phosphate and the magnesium salt must be maintained.

\section{Second factorial experiment; variation of amounts of $\mathrm{K}_{2} \mathrm{HPO}_{4}, \mathrm{MgSO}_{4}$ and $\mathrm{NH}_{4} \mathrm{NO}_{3}$ added}

A second factorial experiment was carried out in which $\mathrm{NH}_{4} \mathrm{NO}_{3}, \mathrm{~K}_{2} \mathrm{HPO}_{4}$ and $\mathrm{MgSO}_{4}$ were varied at three concentrations each, $\mathrm{KCl}$ being omitted. A preliminary experiment showed that an increase in the concentration of $\mathrm{NH}_{4} \mathrm{NO}_{3}$ was beneficial; this salt was used at concentrations of $0.0125 \mathrm{M}$, $0.025 \mathrm{M}$ and $0.375 \mathrm{M}$. The preceding experiment indicated that $\mathrm{K}_{2} \mathrm{HPO}_{4}$ should be present at $0.004 \mathrm{M}$ or less; it was tested at $0.001,0.003$ and $0.004 \mathrm{M} ; \mathrm{MgSO}_{4}$ was used at $0.001,0.0015$ and $0.002 \mathrm{M}$. The method of experimentation was exactly as in the previous factorial experiment. The initial $\mathrm{pH}$ values of the solutions were between $6 \cdot 6$ and $7 \cdot 0$; in all cases the acidity increased as growth took place. The results are shown in Table 3 which includes the analysis of variance.

The difference between the three concentrations of $\mathrm{NH}_{4} \mathrm{NO}_{3}$ was not significant, although the highest concentration gave the greater growth; a relatively high concentration of $\mathrm{NH}_{4} \mathrm{NO}_{3}$ seems to be necessary for this fungus. This fact can be correlated with the observations of Johnstone (1931) that apple trees deficient in nitrogen are more resistant to scab disease. There was a significant difference for the three concentrations of added $\mathrm{K}_{2} \mathrm{HPO}_{4}$ and the lowest concentration gave the highest mean weight of mycelium. For $\mathrm{MgSO}_{4}$ there was a difference at the highest concentration tested.

The interaction between $\mathrm{NH}_{4} \mathrm{NO}_{3}$ and $\mathrm{K}_{2} \mathrm{HPO}_{4}$ was significant. With the lowest concentrations of $\mathrm{NH}_{4} \mathrm{NO}_{3}$ the mean weight of mycelium decreased as $\mathrm{K}_{2} \mathrm{HPO}_{4}$ increased from 0.003 to $0.004 \mathrm{M}$. At $0.025 \mathrm{M}-\mathrm{NH}_{4} \mathrm{NO}_{3}$ the mean weight only fell slightly as the concentration of $\mathrm{K}_{2} \mathrm{HPO}_{4}$ increased. With the highest concentration of $\mathrm{NH}_{4} \mathrm{NO}_{3}$ a great decrease in the mean weight was found at the highest $\mathrm{K}_{2} \mathrm{HPO}_{4}$ concentration. The results suggest that at a low concentration of $\mathrm{NH}_{4} \mathrm{NO}_{3}$ only a low concentration of $\mathrm{K}_{2} \mathrm{HPO}_{4}$ could be tolerated. At a higher concentration of $\mathrm{NH}_{4} \mathrm{NO}_{3}$ the concentration of $\mathrm{K}_{2} \mathrm{HPO}_{4}$ had little effect possibly because the $\mathrm{NH}_{4} \mathrm{NO}_{3}$ had not yet reached a critical concentration. With the highest concentration of $\mathrm{NH}_{4} \mathrm{NO}_{3}$ the lowest concentration of $\mathrm{K}_{2} \mathrm{HPO}_{4}$ gave the best growth.

The interaction between $\mathrm{K}_{2} \mathrm{HPO}_{4}$ and $\mathrm{MgSO}_{4}$ was significant. At the lowest concentration of $\mathrm{K}_{2} \mathrm{HPO}_{4}$ the mean weight of fungus decreased as the concentration of $\mathrm{MgSO}_{4}$ increased, but with the highest concentration of $\mathrm{K}_{2} \mathrm{HPO}_{4}$ 
the greatest mean weight was produced. Thus, again, a balance between these salts is important, and when the $\mathrm{K}_{2} \mathrm{HPO}_{4}$ concentration is increased above a certain level that of the $\mathrm{MgSO}_{4}$ must also be increased. The interaction between $\mathrm{NH}_{4} \mathrm{NO}_{3}$ and $\mathrm{MgSO}_{4}$ was significant. With the low concentration of $\mathrm{NH}_{4} \mathrm{NO}_{3}$ low $\mathrm{MgSO}_{4}$ was optimal and with the higher $\mathbf{N H}_{4} \mathrm{NO}_{3}$ levels high $\mathrm{MgSO}_{4}$ was optimal.

Table 3. Dry weight of mycelium of Venturia inaequalis after 30 days growth at $20^{\circ}$ on media with different concentrations of certain components

Concentrations of $\mathrm{K}_{2} \mathrm{HPO}_{4}: \mathrm{P}_{1}, \mathrm{P}_{2}, \mathrm{P}_{3}=0.002 \mathrm{M}, 0.003 \mathrm{M}, 0.004 \mathrm{M}$; of $\mathrm{MgSO}_{4}: \mathrm{Mg}_{1}, \mathrm{Mg}_{2}$, $\mathrm{Mg}_{3}=0.001 \mathrm{M}, 0.0015 \mathrm{M}, 0.002 \mathrm{M}$; of $\mathrm{NH}_{4} \mathrm{NO}_{3}\left(\mathrm{~N}_{1}, \mathrm{~N}_{2}, \mathrm{~N}_{3}=0.0125 \mathrm{M}, 0.025 \mathrm{M}, 0.0375 \mathrm{M}\right.$. Difference required between weights for odds of $99: 1=7 \cdot 2 \mathrm{mg}$.)
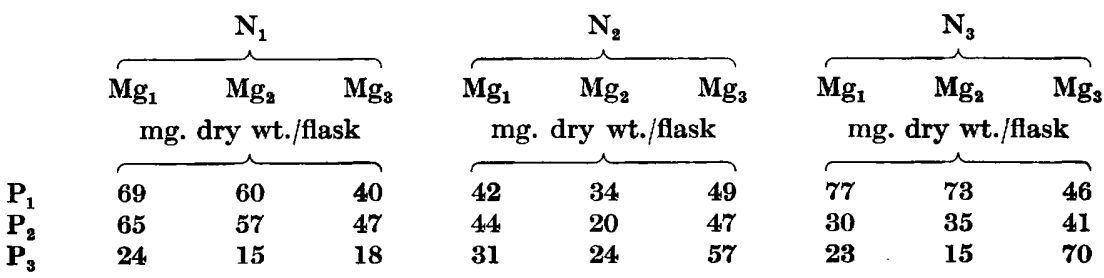

Analysis of variance

(Required ' $F$ ' and ' $t$ ' values taken from Snedecor's tables (1934).)

\begin{tabular}{|c|c|c|c|c|c|c|}
\hline \multirow[b]{2}{*}{ Variance } & \multirow[b]{2}{*}{ D.F. } & \multirow{2}{*}{$\begin{array}{l}\text { Sum of } \\
\text { squares }\end{array}$} & \multirow{2}{*}{$\begin{array}{c}\text { Mean } \\
\text { square }\end{array}$} & \multicolumn{3}{|c|}{ Required odds } \\
\hline & & & & Found & $99: 1$ & $19: 1$ \\
\hline Total & 107 & $46638 \cdot 81$ & $431 \cdot 84$ & — & - & - \\
\hline $\mathrm{NH}_{4} \mathrm{NO}_{3}$ & 2 & $999 \cdot 2$ & $499 \cdot 6$ & $\mathbf{3} \cdot \mathbf{8 1}$ & 4.88 & $3 \cdot 11$ \\
\hline $\mathrm{K}_{2} \mathrm{HPO}_{4}$ & $\overline{2}$ & $10042 \cdot 73$ & $5021 \cdot 36$ & $38 \cdot 29$ & $4 \cdot 88$ & $3 \cdot 11$ \\
\hline $\mathrm{MgSO}_{4}$ & $\overline{2}$ & $1871 \cdot 84$ & $935 \cdot 92$ & $7 \cdot 13$ & $4 \cdot 88$ & $3 \cdot 11$ \\
\hline $\mathrm{NH}_{4} \mathrm{NO}_{3} \times \mathrm{K}_{2} \mathrm{HPO}_{4}$ & 4 & $8310 \cdot 07$ & $2077 \cdot 51$ & $15 \cdot 84$ & $3 \cdot 56$ & $2 \cdot 49$ \\
\hline $\mathrm{NH}_{4} \mathrm{NO}_{3} \times \mathrm{MgSO}_{4}$ & 4 & $4712 \cdot 59$ & $1178 \cdot 14$ & 8.98 & $\mathbf{3 \cdot 5 6}$ & $2 \cdot 49$ \\
\hline $\mathrm{K}_{2} \mathrm{HPO}_{4} \times \mathrm{MgSO}_{4}$ & 4 & $6511 \cdot 94$ & $1627 \cdot 98$ & $12 \cdot 41$ & $3 \cdot 56$ & $2 \cdot 49$ \\
\hline $\mathrm{K}_{2} \mathrm{HPO}_{4} \times \mathrm{MgSO}_{4} \times \mathrm{NH}_{4} \mathrm{NO}_{3}$ & 8 & $3568 \cdot 92$ & $446 \cdot 11$ & $3 \cdot 40$ & $\mathbf{2 \cdot 7 4}$ & $2 \cdot 06$ \\
\hline Error & 81 & $10621 \cdot 52$ & $131 \cdot 12$ & 一 & - & - \\
\hline
\end{tabular}

The analysis of variance also shows that the interaction of all three salts was significant. The higher mean weights were obtained with the highest concentration of $\mathrm{NH}_{4} \mathrm{NO}_{3}$. There was little difference between the mean weights for $0.0125 \mathrm{M}-\mathrm{NH}_{4} \mathrm{NO}_{3}, 0.002 \mathrm{M}-\mathrm{K}_{2} \mathrm{HPO}_{4}$ and $0.001 \mathrm{M}-\mathrm{MgSO}_{4}$, and for $0.0375 \mathrm{M}-$ $\mathrm{NH}_{4} \mathrm{NO}_{3}, 0.004 \mathrm{M}-\mathrm{K}_{2} \mathrm{HPO}_{4}$ and $0.002 \mathrm{M}-\mathrm{MgSO}_{4}$. This again suggests that a balance between the salts is important.

\section{Third factorial experiment; the importance of a balanced solution}

The two previous factorial experiments showed that a definite balance was required between the concentrations of $\mathrm{K}_{2} \mathrm{HPO}_{4}$ and $\mathrm{MgSO}_{4}$, while the second experiment showed a significant second-order interaction between these two salts and $\mathrm{NH}_{4} \mathrm{NO}_{3}$. A third experiment was designed to test the change in the amount of growth which might result when the concentrations of the salts were varied while still maintaining the balance between them. The ratio of 
$\mathrm{K}_{2} \mathrm{HPO}_{4}: \mathrm{MgSO}_{4}$ was $0.002 \mathrm{M}: 0.001 \mathrm{~m}$. The concentration of these salts was decreased to half in one set of solutions and increased twice and then 4 times in other solutions. Each of these solutions was tested with $\mathbf{0 . 0 1 2 5 , 0 . 0 3 7 5}$ and $0.0625 \mathrm{M}-\mathrm{NH}_{4} \mathrm{NO}_{3}$. As in previous experiments the carbon source and vitamins were not varied. Thus twelve different solutions were tested each in five replicates; in each case the $\mathbf{p H}$ value was adjusted to $5 \cdot 8$. The results are seen in Table 4. The mean weight of mycelium for the lowest concentration of $\mathrm{NH}_{4} \mathrm{NO}_{3}$, i.e. $66 \mathrm{mg}$., was lower than that obtained with the higher concentrations (144 and $135 \mathrm{mg}$.), but the latter were not significantly different

Table 4. Growth responses of Venturia inaequalis to different ratios of $\mathrm{K}_{2} \mathrm{HPO}_{4}$ and $\mathrm{MgSO}_{4}$ with the same balance and different concentrations of $\mathrm{NH}_{4} \mathrm{NO}_{3}$

The twelve different solutions numbered in brackets (1)-(12) are referred to in the text below as treatments.

\begin{tabular}{|c|c|c|c|c|}
\hline & & \multicolumn{3}{|c|}{$\mathrm{NH}_{4} \mathrm{NO}_{3}(\mathrm{M})$} \\
\hline & & 0.0125 & 0.0375 & 0.0625 \\
\hline \multirow[b]{2}{*}{$\mathrm{K}_{2} \mathrm{HPO}_{4}(\mathrm{M})$} & \multirow[b]{2}{*}{$\mathrm{MgSO}_{4}(\mathrm{M})$} & \multicolumn{3}{|c|}{ Mean dry-wt. (mg./flask) } \\
\hline & & & & \\
\hline 0.001 & $0 \cdot 0005$ & $30(1)$ & 84 (5) & $88(9)$ \\
\hline 0.002 & $0 \cdot 001$ & $50(2)$ & $139(6)$ & $129(10)$ \\
\hline 0.004 & $0 \cdot 002$ & $84(3)$ & $177(7)$ & $154(11)$ \\
\hline $0 \cdot 008$ & 0.004 & $100(4)$ & $175(8)$ & $170(12)$ \\
\hline
\end{tabular}

from one another. The highest weight of mycelium was obtained with $0.0375 \mathrm{M}-$ $\mathrm{NH}_{4} \mathrm{NO}_{3}$. Within each concentration of $\mathrm{NH}_{4} \mathrm{NO}_{3}$ the mean weights of the five replicates increased as the concentrations of $\mathrm{K}_{2} \mathrm{HPO}_{4}$ and $\mathrm{MgSO}_{4}$ were increased, although the balance between the salts remained the same. At the lowest concentration of $\mathrm{NH}_{4} \mathrm{NO}_{3}$ the first three treatments (nos. 1-3) were different from one another, but treatment no. 4 was not significantly different from treatment no. 3. With $0.0375 \mathrm{M}-\mathrm{NH}_{4} \mathrm{NO}_{3}$ the same effect was produced. The three lower concentrations of $\mathrm{K}_{2} \mathrm{HPO}_{4}$ and $\mathrm{MgSO}_{4}$ gave mean weights different from one another but treatment no. 7 was not significantly different from treatment no. 8. The four treatments with $0.0625 \mathrm{M}-\mathrm{NH}_{4} \mathrm{NO}_{3}$ all gave mean weights different from one another. These results show that the effects of the balance between $\mathrm{K}_{2} \mathrm{HPO}_{4}$ and $\mathrm{MgSO}_{4}$ only operated after a certain concentration had been reached and then only in the two lower concentrations of $\mathrm{NH}_{4} \mathrm{NO}_{3}$, which suggests that this salt must also be in balance with the other two. The highest mean weight of mycelium was produced by the solution containing 0.004 $\mathrm{M}-\mathrm{K}_{2} \mathrm{HPO}_{4}, 0.002 \mathrm{M}-\mathrm{MgSO}_{4}$ and $0.0375 \mathrm{M}-\mathrm{NH}_{4} \mathrm{NO}_{3}$.

In another experiment the concentration of glucose was varied $(1,3,4$ or $8 \%$ ), with $\mathrm{NH}_{4} \mathrm{NO}_{3}$ at 0.0125 or $0.0375 \mathrm{M}$. Mean dry weights of mycelium were taken after 20, 25 and 30 days of growth. In each case high weights were obtained with $8 \%$ glucose and $0.0375 \mathrm{M}-\mathrm{NH}_{4} \mathrm{NO}_{3}$; but at this concentration of glucose the growth of the fungus became very mucilaginous, perhaps indicating abnormal growth. Glucose at $4 \%$ remains that concentration which gives a normal mycelium with the highest dry weight of fungus. 


\section{CONCLUSION}

It is concluded from this work that a medium containing $0.004 \mathrm{M}-\mathrm{K}_{2} \mathrm{HPO}_{4}$, $0.002 \mathrm{M}-\mathrm{MgSO}_{4}, 0.0375 \mathrm{M}-\mathrm{NH}_{4} \mathrm{NO}_{3}, 4 \%(\mathrm{w} / \mathrm{v})$ glucose, $\mathrm{Zn}$ and $\mathrm{Mn}$ at 2 p.p.m. and sufficient amounts of thiamine, pyridoxine, nicotinic acid, folic acid and ascorbic acid, gives a maximum growth in liquid cultures when grown at $\mathrm{pH} 5.8$ and $20^{\circ}$ for 30 days. Although raffinose and cellobiose gave greater yields than glucose, the latter remains the common sugar which gives good growth. The factorial experiments support the conclusion of Talley \& Blank (1941), who also worked with a parasitic fungus, that a proper balance between the major mineral constituents of the culture medium is necessary. But they do not confirm the conclusions of Fothergill \& Raine (1954), who worked with a saprophytic fungus and found that while a balance of salts was important, some other factor (or factors) was also involved in those processes which lead to increases of dry weight of the mycelium. A balance between the carbon and nitrogen sources is also essential.

\section{REFERENCES}

Ezekiel, W. N., Taubenhaus, J. J. \& Fudge, J. F. (1934). Nutritional requirements of the root rot fungus Phymatotrichum omnivorum. Plant Physiol. 9, 187.

Fothergild, P. G. \& Raine, L. C. D. P. (1954). The mineral nutritional requirements of Mucor hiemalis Wehm. J. gen. Microbiol. 10, 17.

Johnstone, K. H. (1931). Observations on the varietal resistance of the apple to scab (Venturia inaequalis Aderh.) with special reference to its physiological aspects. J. Pomol. 9, 30, 195.

KeItT, G. W. \& LANGFond, M. H. (1941). Venturia inaequalis (Cke.) Wint. 1-A groundwork for genetic studies. Amer. J. Bot. 28, 805.

Leben, C. C. \& KeItT, G. W. (1948). Venturia inaequalis. 5-The influence of carbon and nitrogen sources and vitamins on growth in vitro. Amer. J. Bot. $35,337$.

SNEDECOR, G. W. (1934). Calculation and interpretation of analysis of variance and co-variance. Ames, Iowa: Iowa State Col., Div. Industr. Sci. Monogr. 1.

Talley, P. \& Blank, L. M. (1941). A critical study of the nutritional requirements of Phymatotrichum omnivorum. Plant Physiol. 16, 1. 